\title{
Adsorption and Degradation of Ketoprofen in Soils
}

\author{
Jian Xu* Nankai University \\ Weiping Chen Chinese Academy of Sciences \\ Laosheng Wu University of California-Riverside \\ Andrew C. Chang University of California-Riverside
}

Ketoprofen, a nonsteroidal anti-inflammatory drug (NSAID), was commonly found in treated wastewater due to its incomplete removal during sewage treatment plant processes. As treated wastewater is increasingly used for landscape irrigation, it is imperative to understand the leaching potential for ketoprofen in receiving soils. In this study, adsorption and degradation experiments were conducted in four U.S. soils with different physicochemical characteristics. Ketoprofen was not strongly adsorbed to the four soils with $\mathrm{K}_{\mathrm{d}}$ values ranging from 1.26 to $8.24 \mathrm{~L} \mathrm{~kg}^{-1}$, suggesting its potential to move downward with percolating water. The adsorption was positively related to the soil organic matter $(\mathrm{OM})$ content $\left(R^{2}=0.890\right)$. Degradation experiment showed that half-lives $\left(t_{1 / 2}\right)$ of ketoprofen were 4.58 $\mathrm{d}$ in Arlington sandy loam (ASL, coarse-loamy, mixed, active, thermic Haplic Durixeralfs), $8.04 \mathrm{~d}$ in Hanford loamy sand (HLS, coarse-loamy, mixed, superactive, nonacid, thermic Typic Xerorthents), $15.37 \mathrm{~d}$ in Imperial silty clay (ISC, fine, semectitc, calcareous, hyperthermic Vertic Torrifluvents), and $27.61 \mathrm{~d}$ in Palouse silt loam (PSL) soil (fine-silty, mixed, superactive, mesic Pachic Ultic Haploxerolls), respectively. Degradation of ketoprofen in soils appeared to be influenced by the soil $\mathrm{OM}$ content. The prolonged $t_{1 / 2}$ by sterilization indicated that microbial degradation was the dominant pathway for ketoprofen degradation in soils, while photodegradation only contributed a small portion to the ketoprofen degradation. The $\mathrm{t}_{1 / 2}$ and $\mathrm{K}_{\mathrm{oc}}$ values were fitted to screening models to predict the leaching potential of ketoprofen in soils. It appeared that relatively high leaching potential of ketoprofen existed in ISC and PSL soils.
Copyright $\odot 2009$ by the American Society of Agronomy, Crop Science Society of America, and Soil Science Society of America. All rights reserved. No part of this periodical may be reproduced or transmitted in any form or by any means, electronic or mechanical, including photocopying, recording, or any information storage and retrieval system, without permission in writing from the publisher.

Published in J. Environ. Qual. 38:1177-1182 (2009). doi:10.2134/jeq2008.0347

Received 1 Aug. 2008.

*Corresponding author (xujian@nankai.edu.cn). ( $)$ ASA, CSSA, SSSA

677 S. Segoe Rd., Madison, WI 53711 USA
TONSTERoIdAL anti-inflammatory drugs, usually abbreviated 1 to NSAIDs, are widely used pharmaceutical products with analgesic, antipyretic and, in higher doses, anti-inflammatory effects. These drugs are associated with an undisputable success in treating a variety of conditions, such as reducing pain, fever, and inflammation (Musa et al., 2007). It is estimated that they have an annual production of several kilotons. The NSAIDs are introduced primarily after medication via urinal or fecal excretion into sewage treatment plants, where they are not eliminated efficiently due to their designed characteristics of lipophilic and biologically persistent (Perez-Estrada et al., 2005). The concentrations of NSAIDs in river waters were in the range of several hundred nanograms per liter (Stan and Heberer, 1997; Ollers et al., 2001; Farre et al., 2001; Kosjek et al., 2005). The discharge of these pharmaceuticals from production facilities, hospitals, and private household effluent as well as improper disposal of unused drugs has posed a burden on the environment (Kosjek et al., 2005). When the reclaimed wastewater is reused, the NSAID residues may affect the consumers.

Ketoprofen, 2-(3-benzoylphenyl)-propionic acid $\left(\mathrm{C}_{16} \mathrm{H}_{14} \mathrm{O}_{3}\right)$, is one of the arylpropionic acid class of NSAIDs that is commonly used for analgesic and antipyretic effects. It was commonly found in wastewater effluents and surface waters (Heberer et al., 1998; Tixier et al., 2003; Kolpin et al., 2002). Besides the occurrence in aquatic environments, it also can be introduced into terrestrial environment via treated wastewater irrigation on landscape or agricultural soils. The study of environmental behaviors of ketoprofen was focused on its photodegradation in aquatic environment (Bosca et al., 1994; Lin and Reinhard, 2005; Musa et al., 2007). A few studies were conducted to investigate its biodegradation in sewage sludge (Kimura et al., 2007) and in sewage effluent (Yu et al., 2006). To fully understand its potential for causing adverse environmental effects, for example, contamination of groundwater, the study of two environmental processes, adsorption and degra-

L. Wu and A.C. Chang, Dep. of Environmental Sciences, Univ. of California, Riverside, CA 92521; J. Xu, Key Lab. of Pollution Processes and Environmental Criteria, Ministry of Education, College of Environmental Science and Engineering, Nankai Univ., Tianjin, 300071, China; W. Chen, State Key Lab. of Urban and Regional Ecology, Research Center for Eco-Environmental Sciences, Chinese Academy of Sciences, Beijing, 100085, China. Research was performed at the Univ. of California, Riverside.

Abbreviations: ASL, Arlington sandy loam; EDCs, endocrine disrupting compounds; GC/MSD, gas chromatography-mass selected detector; GUS, groundwater ubiquity score; HLS, Hanford loamy sand; ISC, Imperial silty clay; MTBSTFA, $\mathrm{N}$-tert-butyldimethylsilyl-N-methyltrifluoroacetamide; NSAIDs, nonsteroidal antiinflammatory drugs; OM, organic matter; PPCPs, pharmaceuticals and personal care products; PSL, Palouse silt loam; SPE, solid-phase extraction. 
dation, is greatly needed. Adsorption and degradation are two governing processes for deciding the mobility and persistence of organic contaminants in soils, and their parameters derived from standard laboratory tests can be used for the parametrization of mathematical models to assess chemical leaching potential (Pantelelis et al., 2006). Occurrence of ketoprofen in groundwater samples has been reported (Nakada et al., 2008), indicating that it might have leaching potential to contaminate groundwater.

Degradation is a fundamental attenuation process governed by both abiotic and biotic factors for chemicals in soil (Guo et al., 2000), which is affected by a variety of interactions among microorganisms, various soil constituents, and the specific chemical involved. Sorption is the similarly key to controlling chemical advective-dispersive transport, transformation, and bioaccumulation processes (Boivin et al., 2005). In this study, adsorption and degradation behavior of ketoprofen were investigated in four soils with various physicochemical properties. The mechanism of degradation was further investigated through comparative experiments using sterilized and nonsterile soils, with or without light. Parameters obtained from batch experiment were also fitted to two screening models to assess the leaching potential of ketoprofen in different soils. The results should help to assess the threat posed by effluent-derived contaminants to the groundwater as well as provide an indication of potential management options that could be used to alleviate any risks.

\section{Materials and Methods}

\section{Chemicals}

The standard compound ketoprofen was purchased from MP Biomedicals (Solon, OH). Figure 1 presents the chemical structure of ketoprofen. Stock solution was prepared by dissolving ketoprofen in methanol. Derivatizing reagent, N-tert-butyldimethylsilyl-N-methyltrifluoroacetamide (MTBSTFA) was purchased from Sigma-Aldrich (St. Louis, MO). Other solvents used in this study were all of pesticide or HPLC grade.

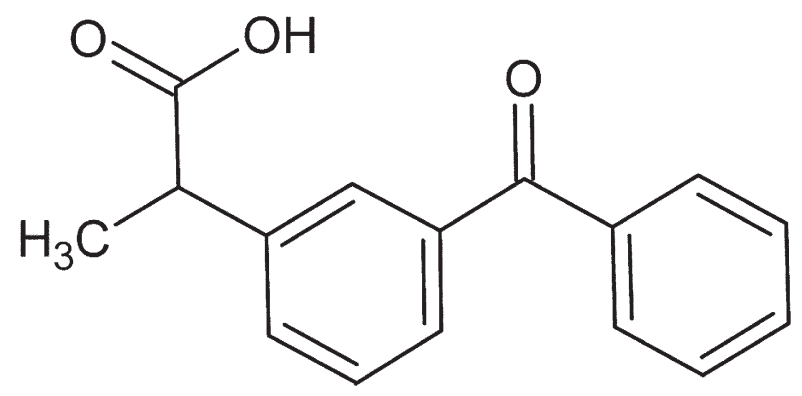

Fig. 1. Chemical structure of ketoprofen.

Table 1. Textural and chemical properties of the four test soils.

\begin{tabular}{lrrrrrl}
\hline Soil & Clay & Sand & Silt & OM & pH & $\mathbf{f}_{\text {oc }}$ \\
\cline { 2 - 5 } & \multicolumn{7}{c}{$\%$} & $\%$ & & $\%$ \\
HLSt & 3.6 & 95.6 & 0.8 & 0.58 & 7.54 & 0.44 \\
ASL & 12.5 & 70.9 & 16.6 & 1.93 & 7.06 & 0.55 \\
ISC & 42.5 & 10.8 & 46.7 & 2.46 & 7.48 & 1.43 \\
PSL & 18.1 & 32.2 & 49.7 & 5.45 & 7.14 & 3.16 \\
\hline
\end{tabular}

† HLS, Hanford loamy sand; ASL, Arlington sandy loam; ISC, Imperial silty clay; PSL, Palouse silt loam.

\section{Soils}

Four soils, HLS, ASL, ISC, and PSL were selected as the experimental media. Soil samples were collected from the 0 - to 20$\mathrm{cm}$ surface layer, air-dried, and ground to pass through a sieve with 2-mm openings. Particle size analysis was determined by the hydrometer method (Gee and Bauder, 1986) and OM content by the $450^{\circ} \mathrm{C}$ combustion method (Davies, 1974). Soil $\mathrm{pH}$ values in $0.005 \mathrm{~mol} \mathrm{~L}^{-1} \mathrm{CaCl}_{2}$ with soil to solution ratio of $1: 1$ were determined with a $\mathrm{pH}$ meter. Their mechanical composition and basic chemical properties are presented in Table 1.

\section{Adsorption Experiment}

Adsorption of ketoprofen in soils was determined using batch equilibrium method. Five grams of each soil (dry weight equivalent) were weighed into a $50-\mathrm{mL}$ Teflon centrifuge tube, and $10 \mathrm{~mL}$ of $0.01 \mathrm{~mol} \mathrm{~L}^{-1} \mathrm{CaCl}_{2}$ solution containing ketoprofen at $0,0.5,1.0,2.5,5.0$, and $10 \mathrm{mg} \mathrm{L}^{-1}$ was added. The solution also contained $0.1 \% \mathrm{HgCl}_{2}$ to inhibit microbial degradation during the period of equilibration. Mercuric chloride was considered the most effective soil sterilization method as it caused the least changes in the soil properties (Wolf et al., 1989), and our preliminary study also showed that the presence of mercury ion did not influence the adsorption of ketoprofen on soils. The soil samples were equilibrated on a mechanical shaker for $24 \mathrm{~h}$ at room temperature $\left(20 \pm 2^{\circ} \mathrm{C}\right)$. This period was selected as a result of a preliminary study showed that the adsorption equilibrium was achieved in $24 \mathrm{~h}$. After equilibration, samples were centrifuged at $6708 \times g$ for $10 \mathrm{~min}$ to separate the solid and aqueous phases. The supernatants were decanted, followed by liquid-liquid extraction with dichloromethane. The organic dichloromethane phase was dried over anhydrous $\mathrm{Na}_{2} \mathrm{SO}_{4}$, concentrated, derivatized with MTBSTFA, and analyzed with gas chromatography-mass selected detector (GC/MSD) to obtain aqueous phase concentration, $\mathrm{C}_{\mathrm{w}}\left(\mathrm{mg} \mathrm{L}^{-1}\right)$. The liquid-liquid extraction procedure gave recovery $>78 \%$ for ketoprofen. The remaining soil phase was extracted as procedures described below. The centrifuge tubes were individually weighed before and after the removal of aqueous phase to estimate the amount of solution that remained in the soil after phase separation. The adsorbed concentration, $\mathrm{C}_{\mathrm{s}}\left(\mathrm{mg} \mathrm{kg}^{-1}\right)$, was calculated from the difference between the amount of chemicals recovered from soil extraction, and the amount remaining in the residual water. The $\mathrm{C}_{\mathrm{w}}$ and $\mathrm{C}_{\mathrm{s}}$ values were fitted to the Freundlich equation $\mathrm{C}_{s}=\mathrm{K}_{\mathrm{f}} \mathrm{C}_{\mathrm{w}}{ }^{\mathrm{n}}$ to estimate $\mathrm{K}_{\mathrm{f}}$ and $\mathrm{n}$. The $\mathrm{K}_{\mathrm{oc}}$ values were calculated by the equation: $\mathrm{K}_{\mathrm{oc}}=\mathrm{K}_{\mathrm{d}} / \mathrm{f}_{\text {oc }}$, where $\mathrm{K}_{\mathrm{d}}\left(=\mathrm{C}_{\mathrm{s}} / \mathrm{C}_{\mathrm{w}}\right)$ values were shown as ranges within the tested concentrations for all measured data.

\section{Degradation Experiment}

Laboratory incubation experiments were conducted to study the degradation of ketoprofen in the soils. An aliquot $(1.0 \mathrm{~mL})$ of ketoprofen in stock solution $\left(10.0 \mathrm{mg} \mathrm{L}^{-1}\right.$ in methanol) was mixed with $10 \mathrm{~g}$ of soil. Acetone was added to ensure the spiked compound was evenly distributed in the soil. The solvents in the spiked soils were allowed to evaporate at room temperature in a darkened fume hood for $15 \mathrm{~h}$. The spiked 
samples $\left(1.0 \mathrm{mg} \mathrm{kg}^{-1}\right)$ were then thoroughly mixed with a sufficient mass of untreated soil to attain the desired concentrations. Five grams of soil sample were placed in a $50 \mathrm{~mL}$ screwtop Teflon centrifuge tube, and deionized water was added to keep $70 \%$ of the water holding capacity. Centrifuge tubes were weighed, and water was added every other day for evaporation loss if necessary. Duplicate soil samples were analyzed for each treatment on Days $0,1,3,5,8,12,16,23,30$, and 45 .

To investigate the degradation mechanism of ketoprofen in soils, the degradation was performed under different experimental conditions. In addition to the soil types, variables such as light exposure and sterilization were also considered. These tests were conducted only in Hanford loamy sand soil. Sterilization was achieved by addition of $0.1 \% \mathrm{HgCl}_{2}$ in soil samples. Darkness was achieved by wrapping the tubes with aluminum foil.

\section{Analysis of Ketoprofen in Soil Samples}

Ketoprofen in soils was determined according to the procedures described by Xu et al. (2008). In brief, $5 \mathrm{~mL}$ of acetoneethyl acetate $(1: 1, \mathrm{v} / \mathrm{v})$ were added into a 50-mL Teflon centrifuge tube containing soil samples. The tube was ultrasonicated for $15 \mathrm{~min}$, centrifuged at $6708 \times \mathrm{g}$ for $10 \mathrm{~min}$, and decanted the supernatant. The soil was extracted three more times, and the supernatants were combined and were $\mathrm{N}$-evaporated in a water bath at $40^{\circ} \mathrm{C}$ to about $1 \mathrm{~mL}$. The extract was redissolved in $500 \mathrm{~mL}$ of deionized water, and a solid-phase extraction (SPE) procedure was applied. The SPE cartridges were eluted with ethyl acetate, and the extracts were dried over anhydrous sodium sulfate, and reduced to $0.5 \mathrm{~mL}$ with a gentle stream of $\mathrm{N}$ at $40^{\circ} \mathrm{C}$, then transferred into the $\mathrm{GC}$ vial. $100 \mu \mathrm{L}$ of MTBSTFA was added, and the volume was brought to $1 \mathrm{~mL}$ with ethyl acetate. The GC vials were put into GC oven at $70^{\circ} \mathrm{C}$ for $60 \mathrm{~min}$ for derivatization. The method recovery and limits of quantification (LOQ) for ketoprofen were $>89.0 \%$ and $0.4 \mathrm{ng} \mathrm{g}^{-1}$, respectively.

\section{Gas Chromatography-Mass Selected Detector Analysis}

Ketoprofen was determined using an Agilent 6890N GC with 5975C MSD equipped with an Agilent 7683B automatic liquid sampler and an HP-5MS GC column (30 m, 0.25 mm .d., $0.25 \mu \mathrm{m}$ film thickness). Helium was used as the carrier gas,

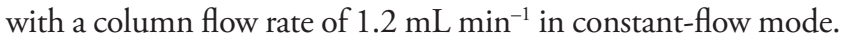
Injector temperature was $250^{\circ} \mathrm{C}$. The GC-MSD interface and the ion source temperatures were set at 280 and $230^{\circ} \mathrm{C}$, respectively. The GC oven temperature was kept at $50^{\circ} \mathrm{C}$ for $1 \mathrm{~min}$, followed by the first ramp at $20^{\circ} \mathrm{C} \mathrm{min}^{-1}$ to $120^{\circ} \mathrm{C}$, second ramp at $10^{\circ} \mathrm{C} \mathrm{m^{-1 }}$ to $280^{\circ} \mathrm{C}$, and holding for $11 \mathrm{~min}$. The mass spectrometer was operated in the selected ion monitoring mode (SIM) with electron impact ionization voltage of $70 \mathrm{eV}$. A $2-\mu \mathrm{L}$ sample was injected in pulsed splitless mode.

\section{Results and Discussion}

\section{Adsorption}

The adsorption isotherms of ketoprofen in the four tested soils are shown in Fig. 2. Adsorption of ketoprofen in soils were well described by the Freundlich equation weighted on $1 / \mathrm{C}_{\mathrm{s}}$ over the range of equilibrium concentrations from 0 to $10 \mathrm{mg} \mathrm{L}^{-1}$, with the correlation coefficient $R^{2}$ ranging from 0.915 to 0.979 (Table 2). The Freundlich adsorption coefficient $\mathrm{K}_{\mathrm{f}}$ ranged from 0.85 to 6.77 . Generally, higher $\mathrm{K}_{\mathrm{f}}$ values were associated with soils with higher OM content (Pantelelis et al., 2006), as indicated in Tables 1 and 2. The nonlinearity factor $n$ was from 0.57 to 1.12 . The $n$ value close to 1 implies that the adsorption isotherm is well fitted to a linear relationship. For the concentration range tested in this study, it is not suitable to fit data to the linear model to estimate the soil/water distribution coefficient $\left(\mathrm{K}_{\mathrm{d}}\right)$. The $\mathrm{K}_{\mathrm{d}}$ was calculated from the equation $\mathrm{K}_{\mathrm{d}}=\mathrm{C}_{\mathrm{s}} / \mathrm{C}_{\mathrm{w}}$ with all measured $\mathrm{C}_{\mathrm{s}}$ and $\mathrm{C}_{\mathrm{w}}$ concentrations from each soil, and their ranges were shown within the test concentration ranges (Table 2 ). The average values of $\mathrm{K}_{\mathrm{d}}$ in different soils were also shown in Table 2 , which were $1.50,1.26,4.36$

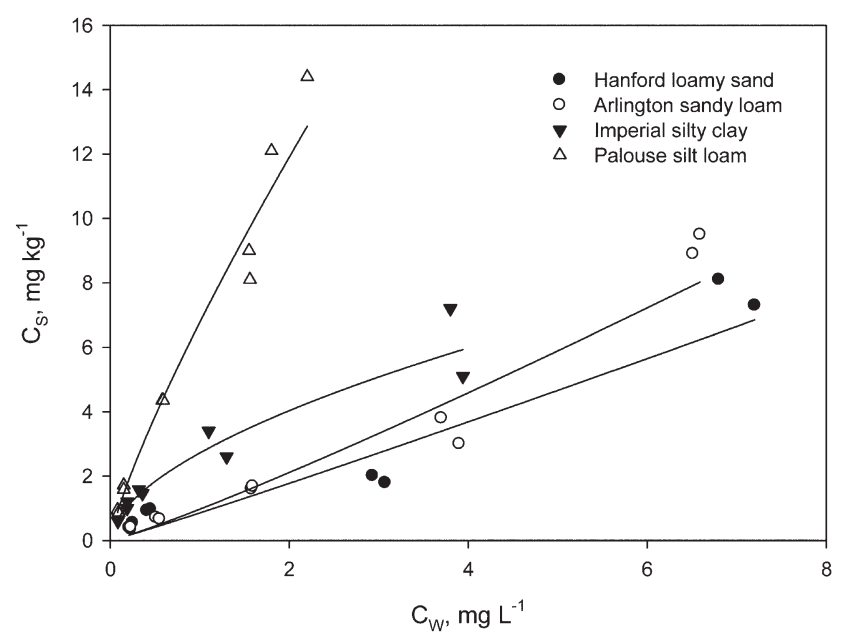

Fig. 2. Adsorption isotherms of ketoprofen in four different soils. Lines are fitted to the Freundlich equation weighted on $1 / C_{s}$.

Table 2. Adsorption coefficients of ketoprofen in four different soils. $\mathrm{K}_{\mathrm{f}}$ and $n$ are Freundlich affinity coefficient and Freundlich linearity index respectively and were calculated with 10 concentrations except for Hanford loamy sand (HLS) with eight. The $\mathrm{K}_{\mathrm{d}}$ and $\mathrm{K}_{\text {oc }}$ values were calculated with all measured data points and shown as average values with standard deviation. Data in parenthesis show $\mathrm{K}_{\mathrm{d}}$ and $\mathrm{K}_{\mathrm{oc}}$ ranges obtained in this study.

\begin{tabular}{|c|c|c|c|c|c|}
\hline Soil & $K_{f}$ & $n$ & $R^{2}$ & $K_{d}$ & $\mathrm{~K}_{\mathrm{oc}}$ \\
\hline & $\mathrm{mg}^{1-\mathrm{n}} \mathrm{L}^{\mathrm{n}} \mathrm{kg}^{-1}$ & & & 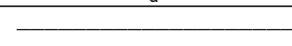 & \\
\hline HLS & $0.85 \pm 0.57$ & $1.05 \pm 0.40$ & 0.915 & $1.50 \pm 0.71(0.58-2.27)$ & $341 \pm 161(132-516)$ \\
\hline ASL† & $0.97 \pm 0.47$ & $1.12 \pm 0.31$ & 0.934 & $1.26 \pm 0.30(0.77-1.78)$ & $229 \pm 54(140-324)$ \\
\hline ISC & $2.72 \pm 0.57$ & $0.57 \pm 0.16$ & 0.941 & $4.36 \pm 2.27(1.29-7.78)$ & $305 \pm 158(90-544)$ \\
\hline PSL & $6.77 \pm 0.92$ & $0.81 \pm 0.17$ & 0.979 & $8.24 \pm 2.40(5.19-11.88)$ & $261 \pm 76(164-376)$ \\
\hline
\end{tabular}

† ASL, Arlington sandy loam; ISC, Imperial silty clay; PSL, Palouse silt loam. 
Table 3. First-order degradation rate constants and correlation coefficients of ketoprofen in soils (spiking level is $0.10 \mathrm{mg} \mathrm{kg}^{-1}$ ).

\begin{tabular}{|c|c|c|c|c|}
\hline Soil & & $k\left(d^{-1}\right)$ & $t_{1 / 2}(d)$ & $R^{2}$ \\
\hline HLSt & & 0.0862 & 8.04 & 0.897 \\
\hline ASL & & 0.1512 & 4.58 & 0.934 \\
\hline ISC & & 0.0451 & 15.37 & 0.933 \\
\hline PSL & & 0.0251 & 27.61 & 0.975 \\
\hline \multirow[t]{3}{*}{ HLS } & Sterile & 0.0163 & 42.51 & 0.918 \\
\hline & Darkness & 0.0689 & 10.06 & 0.907 \\
\hline & Sterile and darkness & 0.0105 & 66.01 & 0.989 \\
\hline
\end{tabular}

† HLS, Hanford loamy sand; ASL, Arlington sandy loam; ISC, Imperial silty clay; PSL, Palouse silt loam.

and $8.24 \mathrm{~L} \mathrm{~kg}^{-1}$ for HLS, ASL, ISC, and PSL, respectively, suggesting that ketoprofen was not strongly adsorbed to the four soils. The adsorption affinity followed a descending order of PSL $>$ ISC > ASL > HLS.

In numerous cases, soil OM has been shown to be highly correlated with organic chemical sorption (Worrall et al., 2001; Spark and Swift, 2002; Ying and Kookana, 2005). In some other cases, chemical adsorption behavior depends on the content of clay in soils (Zhang and Cooper, 1996; Rai et al., 2000; Chen et al., 2006). Analysis of relationships between $K_{d}$ and soil properties indicated that $\mathrm{K}_{\mathrm{d}}$ values of ketoprofen were in a positive correlation with the OM contents in the soils (correlation coefficient $R^{2}=0.890$ ), while the other soil property such as clay contents had little effects on the adsorption of ketoprofen. Organic carbon adsorption coefficient $\mathrm{K}_{\mathrm{oc}}$ is obtained by normalizing adsorption from a total soil basis to an organic carbon basis and is generally regarded as independent of soil for nonionic compounds. Normalization of the $K_{d}$ values in the present study resulted in a smaller variation in $\mathrm{K}_{\text {oc }}$ values among soils, which ranged from 229 to $341 \mathrm{~L} \mathrm{~kg}^{-1}$ (Table 2). These $\mathrm{K}_{\mathrm{oc}}$ values suggest that adsorption of ketoprofen is generally weak in soils, which accordingly implies that ketoprofen may have a high leaching potential to contaminate groundwater.

\section{Degradation}

Degradation data for ketoprofen in soils were fitted to the first-order decay model and showed good performance for all treatments, with $R^{2}$ ranging from 0.897 to 0.989 (Table 3). In the four soils, the most rapid degradation of ketoprofen occurred in ASL soil, with the half-life $t_{1 / 2}$ of $4.58 \mathrm{~d}$, and in PSL ketoprofen was found to have the longest half-life of $27.61 \mathrm{~d}$. Half-lives of ketoprofen in HLS and ISC were 8.04 and $15.37 \mathrm{~d}$, respectively.

There was strong evidence that total soil microbial activity increased with increasing soil OM content (Gaultier et al., 2008), and thereby often enhanced organic chemical degradation (Duahyentumi and Kuwatsuka, 1980; Greer and Shelton, 1992; Singh et al., 2008). However, degradation could decrease with increasing soil OM content because of the increased adsorption of the chemical and thereby reduced bioavailability (Johnson and Sims, 1993; Alexander, 1994). The variation of degradation rate of ketoprofen in different soils should be explained by the combined influence of these factors, and is the result of the balance between different factors. For PSL soil, although it has the highest OM content of the four soils, it also has the highest
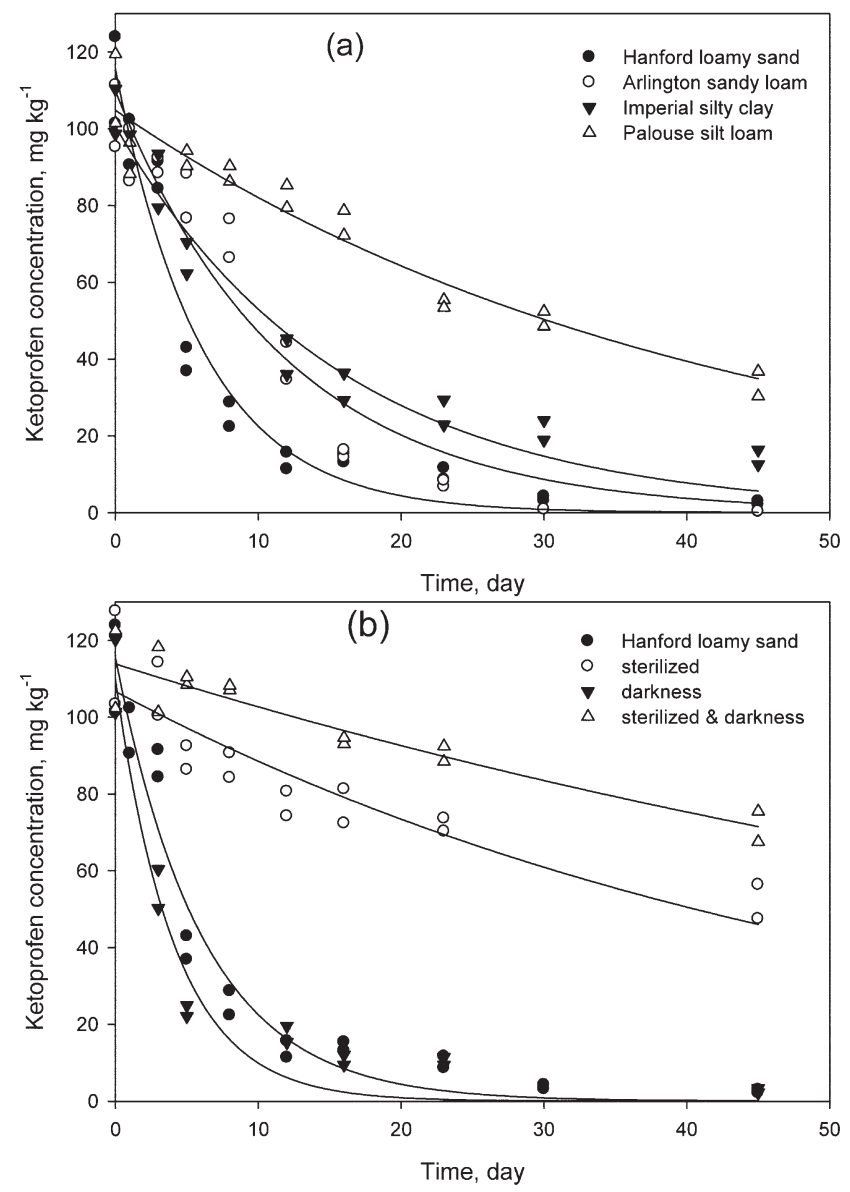

Fig. 3. Degradation of ketoprofen in different soils: (a) in four soils; (b) in Hanford loamy sand with different treatments. Lines are fitted to a first-order decay model.

adsorption capacity for ketoprofen (1.9-7.1 times of the other three soils). Compared with the other three soils, the adsorption here reduced its availability, and resulted in the slow degradation rate. While ASL soil has a weak adsorption of ketoprofen with $\mathrm{K}_{\mathrm{d}}$ value of $1.26 \mathrm{~L} \mathrm{~kg}^{-1}$, and its $\mathrm{OM}$ content of $1.93 \%$ is high enough to maintain the microbial growth. The condition in ASL is favorable for the ketoprofen degradation, which leads to the shortest $\mathrm{t}_{1 / 2}$. Arlington sandy loam soil was also reported to be favorable for the degradation of organophosphate nematicide fosthiazate compared with several other soils (Qin et al., 2004).

Sterilization treatment in HLS showed a decrease in degradation rate of ketoprofen, from $0.0862 \mathrm{~d}^{-1}$ in nonsterile soil to $0.0163 \mathrm{~d}^{-1}$ in sterilized soil (Table 3 and Fig. 3). Degradation of ketoprofen is slowed slightly in darkness, with $k$ decreased from $0.0862 \mathrm{~d}^{-1}$ (with light) down to $0.0689 \mathrm{~d}^{-1}$ (without light). Degradation rate of ketoprofen under both sterile and dark conditions is close to that under sterile conditions, which are 0.0105 and $0.0163 \mathrm{~d}^{-1}$, respectively. Most degradation studies of ketoprofen in the environment were focused on its photodegradation in the aquatic environment. The key reaction in the photodegradation is the very efficient photodecarboxylation of the deprotonated acid (Bosca et al., 1994). Ketoprofen has been suggested to undergo photodegradation and this is a likely rea- 
son for their elimination in the river (Vieno et al., 2005; Nakada et al., 2008). In this study, we simply determined the influence of light on the degradation of ketoprofen in soils by wrapping the Teflon centrifuge tubes with aluminum foil. Considering the facts that the Teflon materials absorbs wavelengths of 300 $\mathrm{nm}$ or less, and only the limited amounts of surface soils were exposed to the visible light, the result from this experimental design demonstrated a rough influence of light. Results from present study indicated that photodegradation of ketoprofen under current conditions was not the significant elimination pathway in soils, although it has a photodegradation half-life of $4.1 \mathrm{~h}$ in river water and $2.5 \mathrm{~min}$ in air-saturated purified water (Lin and Reinhard, 2005). The $t_{1 / 2}$ values in the comparative treatments (with/without light) showed that in darkness the degradation of ketoprofen was only slightly slowed, where $t_{1 / 2}$ was $10 \mathrm{~d}$ compared to the $8 \mathrm{~d}$ with light. The difference between the sterile and sterile and darkness experiments also demonstrated the similar results (Table 3). According to the research by Kreuzig et al. (2003), although diclofenac, a nonsteroidal anti-inflammatory drug, is well-known as a photosensitive compound in watersediment system, photo-induced impacts on the degradability in soils were of subordinate relevance. The observations here suggest that photodegradation behavior of ketoprofen in soils is different from that in aqueous environment, and photodegradation only contributes a small portion to the ketoprofen degradation in soils. To gain insight into the photodegradation of ketoprofen in soils, further investigation needs to be conducted.

A significant difference between sterilized and nonsterile soil suggests that microbial degradation played a key role in the degradation of ketoprofen in the soils. Concerning the biodegradation of ketoprofen in the environment, there are some contradictory comments. Nakada et al. (2008) reported that during their incubation experiment, no microbial degradation was observed for ketoprofen. They ascribed the rapid removal of ketoprofen in estuary to the photodegradation. However, biodegradation is also thought to be the main elimination mechanism under some conditions. Kimura et al. (2007) reported that the main mechanism of elimination of ketoprofen in sludges from municipal wastewater treatment plants by an activated sludge system and membrane bioreactors was found to be biodegradation. Ketoprofen was also classified as the chemical readily biodegradable to exhibit $>80 \%$ biotransformation with Biodegradation Probability Program for Windows (BIOWIN) model (Yu et al., 2006). The present study demonstrates that biodegradation is the dominant pathway for the degradation of ketoprofen in soils.

\section{Leaching Potential of Ketoprofen in Soils}

Adsorption and persistence are usually the two predominant factors influencing the leaching potential of a pesticide in soil. Leaching potential of ketoprofen in soils was calculated using the following groundwater ubiquity score (GUS) (Gustafson, 1989):

$$
\text { GUS }=\log t_{1 / 2} \times\left(4-\log \mathrm{K}_{\mathrm{oc}}\right)
$$

where $\mathrm{K}_{\mathrm{oc}}$ is organic carbon partition coefficient $\left(\mathrm{L} \mathrm{kg}^{-1}\right)$; $\mathrm{t}_{1 / 2}$ is half-life in the soil (days). The model classifies pesticides having GUS scores $\geq 2.8$ as leachers, having GUS scores between 2.8 and 1.8 as transitional, with an uncertain potential to leach, and having GUS scores $<1.8$ as nonleachers. Using measured $t_{1 / 2}$ and $\mathrm{K}_{\mathrm{oc}}$ values, the GUS scores of ketoprofen were 1.33 for HLS, 1.08 for ASL, 1.80 for ISC, and 2.28 for PSL. Therefore, it can be concluded that in HLS and ASL soils, ketoprofen is unlikely to leach through soil to groundwater; while in ISC and PSL soils, ketoprofen is classified as transitional compound, which means the leaching may occur under conducive conditions.

The leaching potential can also be assessed with Cohen's criteria. Cohen et al. (1984) reported that under the following conditions pesticides had high risk potential to contaminate groundwater: $\mathrm{K}_{\mathrm{oc}}$ $<300-500 \mathrm{~L} \mathrm{~kg}^{-1}$; soil t $\mathrm{t}_{1 / 2}>2$ to 3 wk; chemicals were negatively charged at ambient $\mathrm{pH}$; total precipitation and irrigation recharge greater than about $25 \mathrm{~cm} \mathrm{yr}^{-1}$; and soil with a $\mathrm{pH}$ providing high stability to the pesticide residues. In the present study, $\mathrm{K}_{\mathrm{oc}}$ values of ketoprofen in all four soils were lower than $500 \mathrm{~L} \mathrm{~kg}^{-1}$, and in Imperial silty clay and Palouse silt loam soils $t_{1 / 2}$ of ketoprofen were 15.4 and $27.6 \mathrm{~d}$, respectively. According to Cohen's criteria, high leaching potential exists in ISC and PSL soils. This is consistent with the result of GUS model. Half-lives of ketoprofen in HLS and ASL soils were 8.04 and $4.58 \mathrm{~d}$, respectively, thus resulting in low leaching potential to groundwater contamination.

\section{Conclusions}

Laboratory studies showed that ketoprofen was not strongly adsorbed in soils, which may facilitate leaching of ketoprofen under conditions of active water movement. Ketoprofen was mainly degraded via microbial pathway in soils. Longer persistence of ketoprofen in soils with high OM content may be attributed to the increased soil adsorption thereby reduced availability. Leaching models demonstrate that high leaching potential exists under conditions where the chemical is weakly adsorbed and is relatively persistent in the receiving soils (ISC and PSL soils in this study). However, under realistic conditions, many other factors may alter the environmental behavior of the chemical, such as the role of volatilization during the water application, interception by foliage, absorption by plant roots, etc. Further investigation on the actual leaching risk of ketoprofen in soils needs to be conducted under field conditions.

\section{References}

Alexander, M. 1994. Biodegradation and bioremediation. Academic Press, San Diego, CA.

Boivin, A., S. Amellal, M. Schiavon, and M.T. van Genuchten. 2005. 2,4-Dichlorophenoxyacetic acid (2,4-D) sorption and degradation dynamics in three agricultural soils. Environ. Pollut. 138:92-99.

Bosca, F., M.A. Miranda, G. Carganico, and D. Mauleon. 1994. Photochemical and photobiological properties of ketoprofen associated with the benzophenone chromophore. Photochem. Photobiol. 60:96-101.

Chen, W., L.R. Song, N.Q. Gan, and L. Li. 2006. Sorption, degradation and mobility of microcystins in Chinese agriculture soils: Risk assessment for groundwater protection. Environ. Pollut. 144:752-758.

Cohen, S.Z., S.M. Creeger, R.F. Carsel, and C.G. Enfield. 1984. Potential pesticide contamination of groundwater from agricultural uses. p. 297325. In R.F. Krueger and J.N. Seiber (ed.) Treatment and disposal of pesticide wastes. American Chemical Soc., Washington, DC.

Davies, B.E. 1974. Loss-on-ignition as an estimate of soil organic matter. Soil Sci. Soc. Am. Proc. 38:150-151.

Duahyentumi, S., and S. Kuwatsuka. 1980. Effect of organic-matter and 
chemical fertilizers on the degradation of benthiocarb and MCPA herbicides in the soil. Soil Sci. Plant Nutr. 26:541-549.

Farre, M., I. Ferrer, A. Ginebreda, M. Figueras, L. Olivella, L. Tirapu, M. Vilanova, and D. Barcelo. 2001. Determination of drugs in surface water and wastewater samples by liquid chromatography-mass spectrometry: Methods and preliminary results including toxicity studies with Vibrio fischeri. J. Chromatogr. A. 938:187-197.

Gaultier, J., A. Farenhorst, J. Cathcart, and T. Goddard. 2008. Degradation of [carboxyl- ${ }^{14} \mathrm{C}$ ] 2,4-D and [ring- $\mathrm{U}-{ }^{14} \mathrm{C}$ ] 2,4-D in 114 agricultural soils as affected by soil organic carbon content. Soil Biol. Biochem. 40:217-227.

Gee, G.W., and J.W. Bauder. 1986. Particles-size analysis. p. 404-408. In A. Klute (ed.) Methods of soil analysis. Part 1. 2nd ed. Agron. Monogr. 9. ASA and SSSA, Madison, WI

Greer, L.E., and D.R. Shelton. 1992. Effect of inoculant strain and organicmatter content on kinetics of 2.4-dichlorophenoxyacetic acid degradation in soil. Appl. Environ. Microbiol. 58:1459-1465.

Guo, L., W.A. Jury, R.J. Wagenet, and M. Flury. 2000. Dependence of pesticide degradation on sorption: Nonequilibrium model and application to soil reactors. J. Contam. Hydrol. 43:45-62.

Gustafson, D.I. 1989. Groundwater ubiquity score: A simple method for assessing pesticide leachability. Environ. Toxicol. Chem. 8:339-357.

Heberer, T., K. Schmidt-Baumler, and H.J. Stan. 1998. Occurrence and distribution of organic contaminants in the aquatic system in Berlin. Part I: Drug residues and other polar contaminants in Berlin surface and groundwater. Acta Hydrochim. Hydrobiol. 26:272-278.

Johnson, R.M., and J.T. Sims. 1993. Influence of surface and subsoil properties on herbicide sorption by Atlantic and coastal plain soils. Soil Sci. 155:339-348.

Kimura, K., H. Hara, and Y. Watanabe. 2007. Elimination of selected acidic pharmaceuticals from municipal wastewater by an activated sludge system and membrane bioreactors. Environ. Sci. Technol. 41:3708-3714.

Kolpin, D.W., E.T. Furlong, M.T. Meyer, E.M. Thurman, S.D. Zaugg, L.B. Barber, and H.T. Buxton. 2002. Pharmaceuticals, hormones, and other organic wastewater contaminants in US streams, 1999-2000: A national reconnaissance. Environ. Sci. Technol. 36:1202-1211.

Kosjek, T., E. Heath, and A. Krbavcic. 2005. Determination of non-steroidal anti-inflammatory drug (NSAIDs) residues in water samples. Environ. Int. 31:679-685.

Kreuzig, R., C. Kullmer, B. Matthies, S. Holtge, and H. Dieckmann. 2003. Fate and behaviour of pharmaceutical residues in soils. Fresenius Environ. Bull. 12:550-558.

Lin, A.Y.C., and M. Reinhard. 2005. Photodegradation of common environmental pharmaceuticals and estrogens in river water. Environ. Toxicol. Chem. 24:1303-1309.

Musa, K.A.K., J.M. Matxain, and L.A. Eriksson. 2007. Mechanism of photoinduced decomposition of ketoprofen. J. Med. Chem. 50:1735-1743.

Nakada, N., K. Kiri, H. Shinohara, A. Harada, K. Kuroda, S. Takizawa, and H. Takada. 2008. Evaluation of pharmaceuticals and personal care products as water-soluble molecular markers of sewage. Environ. Sci.
Technol. 42:6347-6353.

Ollers, S., H.P. Singer, P. Fassler, and S.R. Muller. 2001. Simultaneous quantification of neutral and acidic pharmaceuticals and pesticides at the low-ng/l level in surface and wastewater. J. Chromatogr. A. 911:225-234.

Pantelelis, I., D.G. Karpouzas, U. Menkissoglu-Spiroudi, and N. Tsiropoulos. 2006. Influence of soil physicochemical and biological properties on the degradation and adsorption of the nematicide fosthiazate. J. Agric. Food Chem. 54:6783-6789.

Perez-Estrada, L.A., S. Malato, W. Gernjak, A. Aguera, E.M. Thurman, I. Ferrer, and A.R. Fernandez-Alba. 2005. Photo-Fenten degradation of diclofenac: Identification of main intermediates and degradation pathway. Environ. Sci. Technol. 39:8300-8306.

Qin, S.J., J.Y. Gan, W.P. Liu, and J.O. Becker. 2004. Degradation and adsorption of fosthiazate in soil. J. Agric. Food Chem. 52:6239-6242.

Rai, A.K., P.K. Chhonkar, and N.P. Agnihotri. 2000. Adsorption-desorption of pendimethalin in six soils of India. J. Indian Soc. Soil Sci. 48:52-56.

Singh, N., D. Hennecke, J. Hoerner, W. Koerdel, and A. Schaeffer. 2008. Mobility and degradation of trinitrotoluene/metabolites in soil columns: Effect of soil organic carbon content. J. Environ. Sci. Health A 43:682-693.

Spark, K.M., and R.S. Swift. 2002. Effect of soil composition and dissolved organic matter on pesticide sorption. Sci. Total Environ. 298:147-161.

Stan, H.J., and T. Heberer. 1997. Pharmaceuticals in the aquatic environment. Analusis 25:M20-M23.

Tixier, C., H. Singer, S. Oellers, and S.R. Muller. 2003. Occurrence and fate of carbamazepine, clofibric acid, diclofenac, ibuprofen, ketoprofen, and naproxen in surface waters. Environ. Sci. Technol. 27:1061-1068.

Vieno, N.M., T. Tuhkanen, and L. Kronberg. 2005. Seasonal variation in the occurrence of pharmaceuticals in effluents from a sewage treatment plant and in the recipient water. Environ. Sci. Technol. 39:8220-8226.

Wolf, D.C., T.H. Dao, H.D. Scott, and T.L. Lavy. 1989. Influence of sterilization methods on selected soil microbiological, physical, and chemical properties. J. Environ. Qual. 18:39-44.

Worrall, F., M. Fernandez-Perez, A.C. Johnson, F. Flores Cesperedes, and E. Gonzalez-Pradas. 2001. Limitations on the role of incorporated organic matter in reducing pesticide leaching. J. Contam. Hydrol. 49:241-262.

Xu, J., L.S. Wu, W.P. Chen, and A.C. Chang. 2008. Simultaneous determination of pharmaceuticals, endocrine disrupting compounds and hormone in soils by gas chromatography-mass spectrometry. J. Chromatogr. A. 1202:189-195.

Ying, G.G., and R.S. Kookana. 2005. Sorption and degradation of estrogenlike-endocrine disrupting chemicals in soil. Environ. Toxicol. Chem. 24:2640-2645.

Yu, J.T., E.J. Bouwer, and M. Coelhan. 2006. Occurrence and biodegradability studies of selected pharmaceuticals and personal care products in sewage effluent. Agric. Water Manage. 86:72-80.

Zhang, S.Q., and J.F. Cooper. 1996. Adsorption, desorption, and degradation of three pesticides in different soils. Arch. Environ. Contam. Toxicol. 30:15-20. 